\title{
Kaposi's Sarcoma following Chronic Lymphocytic Leukemia: A Rare Entity
}

\author{
F. Kose ${ }^{a} \quad$ N.E. Kocer ${ }^{b} \quad$ A.T. Sumbul ${ }^{a} \quad$ A. Sezer ${ }^{a}$ \\ O. Yilkan ${ }^{\mathrm{a}}$ \\ Departments of ${ }^{\mathrm{a}}$ Medical Oncology and ${ }^{\mathrm{b}}$ Pathology, Baskent University Faculty \\ of Medicine, Ankara, Turkey
}

\section{Key Words}

Kaposi's sarcoma · Chronic lymphocytic leukemia · Secondary malignancy

\begin{abstract}
Cutaneous manifestations can occur in the wide range of internal malignancy. They can occur by metastases or local spread, direct infiltration, or a site of primary malignancy itself. Sometimes these manifestations are related with an underlying malignancy but they do not contain malignant cells as paraneoplastic dermatological syndromes. Chronic lymphocytic leukemia (CLL) is the most common leukemia all over the world. Cutaneous lesions occur in up to $25 \%$ of patients. Most commonly seen cutaneous lesions in CLL are those of infectious or hemorrhagic origin. Skin cancer risk was also increased eightfold in CLL when compared with normal population, so cutaneous lesions in CLL can be the first manifestation of secondary skin malignancy. Herein, we report an interesting case of Kaposi's sarcoma which was diagnosed during the course of CLL.
\end{abstract}

\section{Introduction}

Kaposi's sarcoma (KS) is a spindle-cell malignant low-grade vascular tumor associated with human herpesvirus 8 (HHV-8) [1]. It was first published by the dermatologist Moritz Kaposi in the journal Archiv für Dermatologie und Syphilis, in 1872 [2]. In the current literature, four main types of KS are described: (1) epidemic or AIDSrelated KS, (2) KS in immunocompromised patients, (3) classic KS, and (4) endemic or African KS. All four types are seen more often among men than women [3].

Chronic lymphocytic leukemia (CLL) is presented with an increasing number of functionally incompetent mature lymphocytes which are of monoclonal origin, mainly 
in the peripheral blood, bone marrow, and all throughout the reticuloendothelial system. CLL is the most common leukemia in Western countries.

Herein we report an interesting case of KS which was diagnosed during the course of CLL as a secondary malignancy.

\section{Case Report}

A 64-year-old female case presented with complaints of bluish and indurate lesions all over both lower extremities ( $\underline{\text { fig. 1 }}$ ). She was first evaluated in a dermatology out-patient clinic. After initial evaluation, biopsy was done from the lesions and KS was diagnosed ( $\underline{\text { fig. } 2}$, fig. 3 ). The case was referred to the Medical Oncology Department. The patient has had a history of CLL since the year of 1999 but she has not needed any active drug treatment since 1999. She did not have any complication such as bacterial infection or hemolytic anemia throughout the disease course. There was no risk factor in her personal history that disposed the patient to AIDS. Her physical examination revealed hepatosplenomegaly and peripheral lymphadenopathy. Her laboratory workup showed marked lymphocytosis with mature lymphocytes. Laboratory panels for hepatitis B, C and HIV were negative. Quantitative immunoglobulin $\mathrm{M}$ and A levels were decreased, whereas immunoglobulin G level was normal. Abdominal and thoracic CT scan showed widespread lymphadenopathy with hepatosplenomegaly. Endoscopic and colonoscopic evaluation of the gastrointestinal system revealed normal findings. Although all tests were negative for systemic involvement of KS, KS lesions have an allover pattern in both extremities, so we planned to administer systemic chemotherapy which consisted of anthracycline, vincristine, and bleomycine. After three cycles of systemic chemotherapy, the lesions had completely disappeared and there was no toxicity of chemotherapeutics.

\section{Discussion}

Although in the literature, there is a strong relationship between immunosuppression after solid organ transplantation and KS, there is no strong data that shows a relation between CLL and KS. Patients with CLL are prone to the viral, bacterial, and opportunistic infection even without taking any chemotherapeutics. Although immunosuppression in CLL can dispose the patient to the infection, can it cause tending to the formation of secondary malignancy? Hisada et al. [4] reported that KS is 5 times more common in the CLL population than the normal population. In this surveillance study about secondary malignancies preceding CLL diagnosis, Hisada et al. analyzed 16,367 patients with CLL, so we cannot just say that the increased incidence of KS in CLL patients is an incidental finding. Median latency time between diagnosis of CLL and preceding KS was 75 months in this unique study [4].

Over 90 percent of KS cases are infected and probably caused by HHV-8 infection. It is true for all types of KS including AIDS-related KS, KS in immunocompromised patients, classic KS and endemic or African KS [1]. Control of HHV-8 infection is mediated by an antiviral T-cell response to HHV-8 proteins [5]. The development of KS is associated with reactivation of HHV-8 in transplant recipients. Latent HHV-8 infection of endothelial cells can cause subsequent conversion of endothelial cells into the spindle cells. Then the proliferative phase started, and VEGF secretion increased from the infected endothelial cells. This activation plays a pivotal role in the development of the final tumor [6]. Is this a mechanism that causes KS in CLL patient? We know that there is an imbalance in circulating T-cell subpopulations in CLL [7]. So 
theoretically, latent HHV-8 infection can be reactivated in CLL patients and can trigger KS lesions.

In conclusion, CLL can dispose to the development of KS but the exact mechanism is not explained as much as KS preceding solid organ transplantation. So physicians should be very careful about the probability of KS in newly and progressively developing skin lesions in CLL.

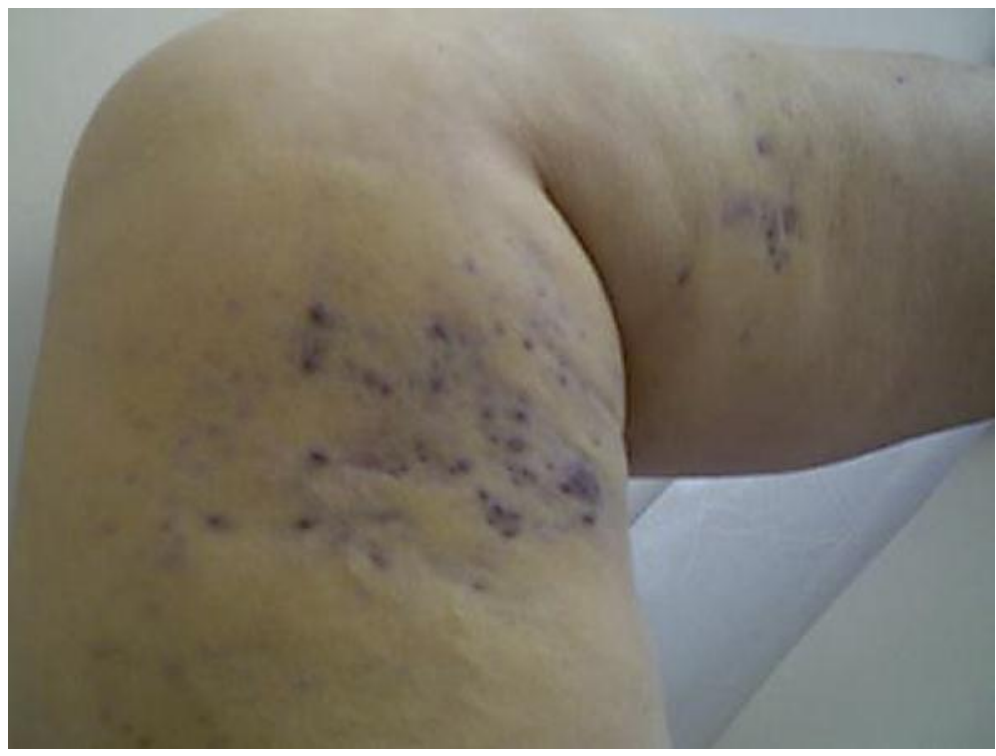

Fig. 1. Bluish and indurate lesions at the lower extremity of the patient.

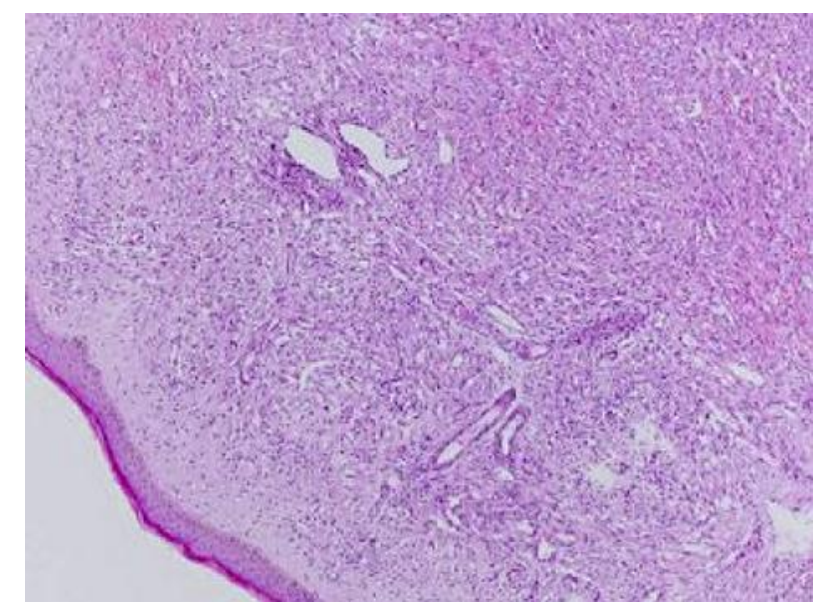

Fig. 2. Nodular lesion composed of vascular spaces and spindle cells $(\mathrm{HE}, \times 100)$. 


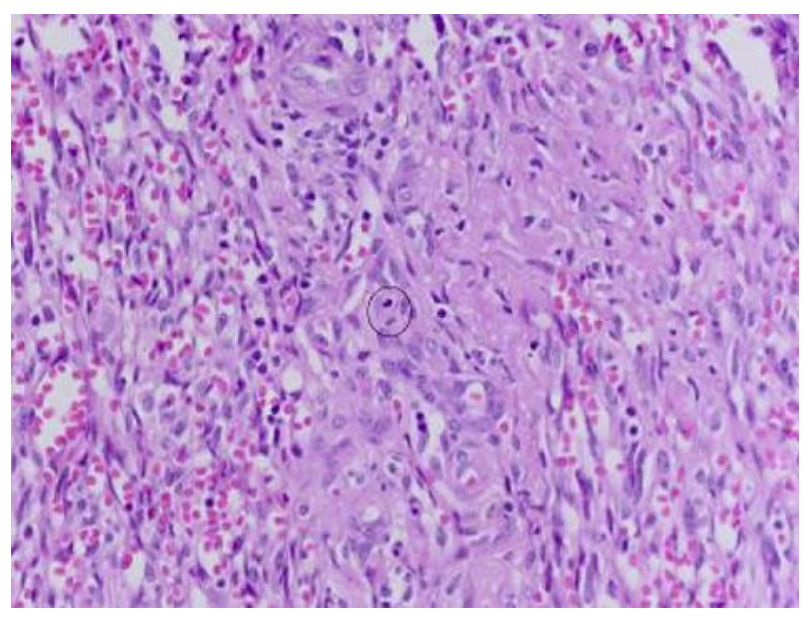

Fig. 3. Vascular spaces containing erythrocytes. Note the mitosis (encircled) (HE, ×400).

\section{References}

1 Moore PS, Chang Y: Detection of herpesvirus-like DNA sequences in Kaposi's sarcoma in patients with and without HIV infection. N Engl J Med 1995;332:1181-1185.

-2 Kaposi M: Idiopatisches multiples Pigmentsarkom der Haut. Arch Dermatol Syph 1872;4:265.

-3 Iscovich J, Boffetta P, Winkelmann R, Brennan P, Azizi E: Classic Kaposi's sarcoma in Jews living in Israel, 1961-1989: a population-based incidence study. AIDS 1998;12:2067-2072.

-4 Hisada M, Biggar RJ, Greene MH, Fraumeni JF Jr, Travis LB: Solid tumors after chronic lymphocytic leukemia. Blood 2001;98:1979-1981.

5 Wang QJ, Jenkins FJ, Jacobson LP, Kingsley LA, Day RD, Zhang ZW, Meng YX, Pellett PE, Kousoulas KG, Baghian A, Rinaldo CR Jr: Primary human herpesvirus 8 infection generates a broadly specific CD8(+) Tcell response to viral lytic cycle proteins. Blood 2001;97:2366-2373.

-6 Campistol JM, Gutierrez-Dalmau A, Torregrosa JV: Conversion to sirolimus: a successful treatment for posttransplantation Kaposi's sarcoma. Transplantation 2004;77:760-762.

-7 Kay NE, Johnson JD, Stanek R, Douglas SD: T-cell subpopulations in chronic lymphocytic leukemia: abnormalities in distribtuion and in in vitro receptor maturation. Blood 1979;54:540-544. 